\title{
Adição de complexo multienzimático em dietas à base de soja extrusada e desempenho de pintos de corte ${ }^{1}$
}

\section{Claudson Oliveira Brito 2 , Luiz Fernando Teixeira Albino ${ }^{3}$, Horacio Santiago Rostagno ${ }^{3}$, Paulo Cezar Gomes ${ }^{3}$, Marli Arena Dionizio ${ }^{4}$, Débora Cristine Oliveira Carvalho ${ }^{4}$}

\author{
${ }_{1}$ Parte da dissertação de Mestrado do primeiro autor, apresentada ao curso de Pós-graduação em Zootecnia de UFV. \\ 2 Zootecnista, Mestre em Nutrição de Monogástricos. \\ ${ }^{3}$ Departamento de Zootecnia - UFV. \\ ${ }^{4}$ Pós-graduação em Zootecnia - UFV.
}

RESUMO - Objetivou-se avaliar os efeitos da adição de complexo multienzimático em dietas à base de soja extrusada submetida a três níveis de processamento sobre o desempenho de frangos de corte de 1 a 21 dias de idade. Foram utilizados 960 pintos de corte machos Avian Farms, em arranjo fatorial $3 \times 2$ (três dietas à base de soja extrusada subprocessada, normal e superprocessada $\times$ dois níveis de adição de complexo multienzimático: 0 e 0,05\%), totalizando seis tratamentos com oito repetições de 20 aves por unidade experimental. As dietas foram formuladas para atender às exigências nutricionais das aves, com exceção da proteína bruta, da lisina e da metionina + cistina, que foram fornecidas em níveis subótimos para facilitar a detecção de diferenças no valor nutritivo. Os valores de solubilidade em $\mathrm{KOH} 0,2 \%$ e de urease das diferentes sojas extrusadas foram respectivamente: subporcessada = $91 \%$ e 0,5 ; processamento normal $=88 \%$ e 0,05 e superprocessada $=66$ e $0,005 \%$. O complexo multienzimático foi composto de celulase, amilase e protease, utilizando-se $500 \mathrm{~mL} / \mathrm{t}$. As aves e as rações foram pesadas no início e ao final da fase experimental (1 a 21 dias), para avaliação do ganho de peso, do consumo de ração e da conversão alimentar. A adição do complexo multienzimático em dietas contendo soja extrusada em diferentes níveis de processamento melhorou o ganho de peso em $3,85 \%$ e a conversão alimentar em 4,24\%, observando-se o maior efeito no desempenho das aves alimentadas com soja extrusada subprocessada, melhorando 4,64\% no ganho de peso e 5,0\% na conversão alimentar. As aves alimentadas com dietas contendo soja extrusada normal apresentaram desempenho superior ao das alimentadas com soja extrusada sub e superprocessada.

Palavras-chave: aditivos, alimento alternativo, enzimas, frangos de corte, processamento

\section{Addition of multienzymatic complex in different extruded full fat soybeans based diets on the broiler performance}

\begin{abstract}
One experiment was conducted to evaluate the effect of the addition of multienzymatic complex in diets with different quality of extruded full fat soybeans on the performance of broiler chicks. A total of 960 Avian Farms male broiler chicks were used from 1 to 21 days of age. The completely randomized experimental design utilized a $3 \times 2$ factorial treatment structure with three extruded full fat soybeans (under, standard and over processed) and two levels of multienzymatic complex addition $(0.0$ and $0.05 \%)$. Total of six treatments and eight replicates of 20 birds for experimental unit. The diets were formulated to contain corn end extruded full fat soybeans, with crude protein, lysine and methionine+cystine below recommended levels to facilitate detection of nutritional differences. The solubility values in $\mathrm{KOH} 0.2 \%$ and urease of the different extruded full fat soybeans they were respectively: under processed $(91 \%$ and 0.5$)$, standard ( $88 \%$ and 0.05$)$ and over processed $(66 \%$ and $0.005 \%)$. The multienzymatic complex was composed with celulase, amylase and protease. The birds and ration were weighted in the initial and final experimental phase to get weigh gain, feed intake and feed conversion. The addition of multienzymatic complex in diets contend extruded soybean with different processing improved weight gain in $3.8 \%$ and the feed conversion in $4.24 \%$. The largest effect of addition was observed with birds fed under processed soybean, where weight gain and feed conversion improved by 4.64 and 5.0\% respectively. Birds fed diets with standard extruded soybean, showed better performance when compared with birds fed with extruded soybean, under and over processed.
\end{abstract}

Key Words: additives, alternative feeding, broiler chicks, enzymes, processing

\section{Introdução}

Atualmente, a avicultura brasileira tem se destacado no cenário internacional pela alta produtividade e qualidade de seus produtos e, para a manutenção deste perfil, é neces- sário o desenvolvimento de estratégias nutricionais para rápido crescimento das aves e redução no ciclo de produção, o que requer rações de melhor qualidade.

Grande parte das rações para frangos de corte ainda é formulada com milho e farelo de soja, que 
possuem bom perfil nutricional. Porém, tem sido proposto o uso de alimentos alternativos, como a soja integral, de alta qualidade protéica e elevada concentração energética. Entretanto, para se utilizar soja integral em substituição ao farelo de soja em rações para frangos de corte, é necessária a redução dos fatores antinutricionais, como os inibidores de tripsina, as lectinas, as lipoxigenases, as antivitaminas e os polissacarídeos não-amiláceos (PNA), ambos redutores do desempenho animal.

Para inativação ou redução destes fatores antinutricionais e manutenção da qualidade nutritiva, vários processamentos térmicos foram desenvolvidos. Jorge Neto (1992) relacionou sete métodos de processamento, destacando-se a extrusão e a tostagem. A extrusão, em especial, é o processo pelo qual os materiais úmidos, amiláceos e proteinosos são cozidos e plasticizados por calor, pressão e cisalhamento mecânico (Smith, 1976).

$\mathrm{O}$ adequado processamento da soja integral é avaliado por metodologias como a solubilidade da proteína em hidróxido de potássio $(\mathrm{KOH}) 0,2 \%$, que fornece valores entre 75 e $90 \%$, e a atividade da urease, com valores de 0,05 a 0,30 . Entretanto, valores acima ou abaixo indicam processamento inadequado. Segundo Marsman et al. (1995), o adequado processo de extrusão aumenta a quebra das proteínas, com maior ação de enzimas digestivas, e o superprocessamento diminui o valor nutricional, pela formação da reação de Maillard.

Sakomura \& Silva (1998a) observaram que frangos de corte alimentados com dieta contendo soja integral extrusada apresentaram melhor desempenho que as aves alimentadas com dietas contendo farelo de soja acrescida de óleo.

Enzimas exógenas têm sido utilizadas como alternativa para melhorar a qualidade de dietas para aves, sendo mais intensamente empregadas em dietas à base de trigo, de centeio e de cevada, visando à redução da viscosidade intestinal, a melhoria na utilização dos nutrientes e o aumento do desempenho (Garcia et al., 2000; Jarori \& Scheideler, 1999).

O uso de complexos enzimáticos com diferentes especificidades tem sido proposto principalmente para dietas à base de milho e farelo de soja, que, apesar de apresentarem boa qualidade nutricional, podem melhorar significativamente o desempenho de aves e de suínos quando adicionados dessas enzimas (Schang et al., 1997; Kitchen, 1997).

Este trabalho foi desenvolvido com o objetivo de avaliar os efeitos da adição de complexo multienzimático (protease, amilase e celulase) em dietas à base de milho e de sojas extrusadas a diferentes níveis de processamento sobre o desempenho de frangos de corte.

\section{Material e Métodos}

Este experimento foi desenvolvido no Setor de Avicultura do Departamento de Zootecnia da Universidade Federal de Viçosa-MG. A temperatura média registrada no período foi de $27,7^{\circ} \mathrm{C}$ e as médias das mínimas e máximas, de 24,8 e $30,6^{\circ} \mathrm{C}$, respectivamente.

Foram utilizados 960 pintos de corte machos Avian Farms, no período de 1 a 21 dias de idade, alojados em galpão de alvenaria telado e coberto com telhas de amianto, subdividido em boxes de 1,1 x 2,0 m, forrados com cama de maravalha.

As dietas foram formuladas com milho e soja extrusada, segundo as recomendações de Rostagno et al. (2000), com exceção da proteína bruta, da lisina e da metionina + cistina, que foram fornecidas em níveis subótimos para facilitar a detecção de diferenças no valor nutritivo, como demonstrado na Tabela 1.

$\mathrm{O}$ delineamento experimental foi inteiramente casualizado, em arranjo fatorial $3 \times 2$ (três tipos de soja extrusada $\times$ dois níveis do complexo multienzimático, $0 \mathrm{e}$ $0,05 \%$ ), totalizando seis tratamentos com oito repetições de 20 aves por unidade experimental (Tabela 2 ).

As sojas subprocessada, normal e superprocessada foram incluídas na proporção fixa de $34 \%$ nas rações experimentais.

O complexo multienzimático (Allzyme Vegpro ${ }^{\circledR}$ ) foi composto de celulase, amilase $(3 \%)$ e protease $(3 \%)$, utilizando-se $500 \mathrm{~mL} / \mathrm{t}$ de dieta, de acordo com as recomendações do fabricante.

As aves e as dietas foram pesadas no início e ao final da fase experimental (1 a 21 dias), para avaliação do ganho de peso, do consumo de ração e da conversão alimentar.

A mortalidade foi registrada para ser considerada durante a correção dos dados de desempenho.

Aos 21 dias de idade, três aves de cada repetição foram pesadas e abatidas por deslocamento cervical e imediatamente dissecadas para retirada do fígado e do pâncreas, que foram pesados e armazenados em copo plástico sob refrigeração.

A avaliação estatística foi feita utilizando-se análise de variância, aplicando-se o teste de Student-Newman-Keul (SNK), para comparação de médias, por meio do programa estatístico SAEG (2000). 
Tabela 1 - Composições percentual e química das dietas experimentais

Table 1 - Ingredient and chemical compositions of experimental diets

\begin{tabular}{|c|c|}
\hline $\begin{array}{l}\text { Ingrediente } \\
\text { Ingredient }\end{array}$ & $\%$ \\
\hline Milho (Corn) & 54,634 \\
\hline $\begin{array}{l}\text { Soja extrusada } \\
\text { (subprocessada, normal e superprocessada) }\end{array}$ & 34,000 \\
\hline \multicolumn{2}{|l|}{ Extruded full fat soy bean } \\
\hline \multicolumn{2}{|l|}{ (under, standard, over processed) } \\
\hline Farelo de soja (Soybean meal) & 7,000 \\
\hline Calcário (Limestone) & 1,000 \\
\hline Fosfato bicálcico & 1,840 \\
\hline \multicolumn{2}{|l|}{ Dicalcium phosphate } \\
\hline L-lisina $\mathrm{HCl} 99 \%$ & 0,050 \\
\hline \multicolumn{2}{|l|}{ L-lysine $\mathrm{HCl} 99 \%$} \\
\hline DL-metionina $99 \%$ & 0,150 \\
\hline \multicolumn{2}{|l|}{ DL- methionine } \\
\hline Sal (Salt) & 0,500 \\
\hline Suplemento vitamínico ${ }^{1}$ (Vitamin supplement) & 0,100 \\
\hline Suplemento mineral ${ }^{1}$ (Mineral supplement) & 0,050 \\
\hline Antioxidante (BHT) (Antioxidant BHT) & 0,010 \\
\hline Anticoccidiano $12 \%$ (Anticoccidial $12 \%$ ) & 0,050 \\
\hline Avilamicina $10 \%$ (Avilamicin $10 \%$ ) & 0,006 \\
\hline Cloreto de colina $60 \%$ (Choline chloride $60 \%$ ) & 0,060 \\
\hline Amido $^{2}$ (Starch) & 0,550 \\
\hline
\end{tabular}

\section{Valores calculados}

Calculated values

Energia metabolizável (kcal/kg)

Metabolizable energy

Proteína bruta (\%) (Crude protein) 20,80

Cálcio (\%) (Calcium)

Fósforo disponível (\%)

Available phosphorus

Sódio (\%) (Sodium)

Met+Cist digestível (\%)

Available $\mathrm{Met}+\mathrm{Ci}$

Lisina digestível (\%)

1,004

Available lysine

${ }^{1}$ Rovimix (Roche) - Níveis de garantia por quilo do produto (guarantee levels for kg/product): vit A - 10.000.000 UI; vit D3 - 2.000.000 UI; vit E - $30.000 \mathrm{UI}$; vit B1 - 2,0 g; vit B6 - 4,0 g; ácido pantotênico (pantothenic acid) - 12,0 g; biotina (biotine) - $0,10 \mathrm{~g}$; vit K3 - 3,0 g; ácido fólico (folic acid) - $1,0 \mathrm{~g}$; ácido nicotínico (nicotinic acid) - 50,0 g; vit B12 - 15.000 mcg; selênio (selenium) - 0, 25 g; e veículo q. s. p (inert filler) - 1.000 g. Roligomix (Roche) - Níveis de garantia por quilo do produto (guarantee levels for $\mathrm{kg} / \mathrm{product}$ ): $\mathrm{Mn}, 16,0 \mathrm{~g}$; Fe, 100,0 g; Zn, 100,0 g; Cu, 20,0 g; Co, 2,0 g; I, 2,0 g; e Veículo q. s. (inert filler) - $1.000 \mathrm{~g}$.

$2 \mathrm{O}$ complexo multienzimático substituiu o amido (The complex multienzymatic replaced starch).

\section{Resultados e Discussão}

Constam na Tabela 3 os resultados da avaliação dos parâmetros de desempenho, ganho de peso, consumo de ração e conversão alimentar.

Entre as aves que não receberam complexo multienzimático (CM) na alimentação, as alimentadas com a dieta contendo soja extrusada com processamento normal (SEN) apresentaram desempenho superior $(\mathrm{P}<0,05)$ ao daquelas alimentadas com dietas contendo soja extrusada subprocessada (SES) e soja extrusada superprocessada (SESP), observando-se que o ganho de peso piorou nas aves alimentadas com SES e SESP em 27,9\% (181,3 g)e 26,9\% (175 g), respectivamente.

Nas aves alimentadas com SES e SESP, a conversão alimentar piorou em $26,1 \mathrm{e} 26,8 \%$, respectivamente, em comparação à conversão daquelas que receberam dietas formuladas com SEN. Entretanto, as aves que consumiram a dieta contendo SESP apresentaram todos o parâmetros de desempenhos similares $(\mathrm{P}<0,05)$ aos das alimentadas com dieta à base de SES.

As diferenças observadas no desempenho apresentaram relação direta com o adequado processamento da soja, pois a soja dentro dos padrões de qualidade favorece a redução dos fatores antinutricionais e a disponibilização de nutrientes para melhor ação enzimática. Essa qualidade de processamento pode ser observada quando se avalia a solubilidade da proteína em hidróxido de potássio $0,2 \%$ e a atividade de urease, preconizadas entre 75 e $90 \%$ e 0,05 e 0,30, respectivamente (Anfar, 1985).

A importância da inativação dos fatores antinutricionais para assegurar o desempenho dos animais foi verificada por Farag (1998), que testou diferentes níveis de radiação (5 a 60 KGy) sob a soja crua e observou que a atividade de urease da soja foi de 1,76 e 0,35 e o ganho de peso das aves, de 180 e 342 g nos níveis de 0 e $15 \mathrm{KGy}$ de radiação, respectivamente. Segundo Marsman et al. (1995), o adequado processo de extrusão aumenta a quebra das proteínas, possibilitando maior

Tabela 2 - Especificações dos tratamentos realizados

Table 2 - Description of treatments

\begin{tabular}{|c|c|c|c|c|}
\hline $\begin{array}{l}\text { Tratamento } \\
\text { Treatment }\end{array}$ & $\begin{array}{l}\text { Processamento da soja } \\
\text { extrusada } \\
\text { Extruded soybean processing }\end{array}$ & $\begin{array}{l}\text { Solubilidade da PB } \\
\text { em } \mathrm{KOH}(\%)^{*} \\
C P \text { Solubility in } \mathrm{KOH}\end{array}$ & $\begin{array}{c}\text { Atividade de urease }(? \mathrm{pH})^{*} \\
\text { Urease activity }\end{array}$ & $\begin{array}{c}\text { Complexo multienzimático } \\
\text { Multienzymatic complex }\end{array}$ \\
\hline 2 & Subprocessada (under processed) & 91 & 0,5 & Com (With) \\
\hline 3 & Normal (standard processed) & 88 & 0,05 & Sem (Without) \\
\hline 4 & Normal (standard processed) & 88 & 0,05 & Com (With) \\
\hline 6 & Superprocessada (over processed) & 66 & 0,0005 & Com (With) \\
\hline
\end{tabular}

* Análise realizada pela Cooperativa dos Granjeiros do Oeste de Minas (COGRAN), Pará de Minas.

* Analysis performed at Cooperative of Farmer of the West of Minas, Pará de Minas. 
Tabela 3 - Efeitos da adição do complexo multienzimático (CM) em dietas com soja extrusada sobre o consumo, o ganho de peso e a conversão alimentar de frangos de corte no período de 1 a 21dias de idade

Table 3 - Effects of increasing levels of multienzymatic complex (MC) on feed intake, weight gain and feed:gain of the broiler chicks fed diets with extruded full fat soybean, 1 to 21 days of age

\begin{tabular}{|c|c|c|c|c|c|c|c|c|c|c|c|c|}
\hline & \multicolumn{4}{|c|}{$\begin{array}{c}\text { Ganho de peso } \\
\text { Weight gain }\end{array}$} & \multicolumn{4}{|c|}{$\begin{array}{c}\text { Consumo de ração } \\
\text { Feed intake }\end{array}$} & \multicolumn{4}{|c|}{$\begin{array}{c}\text { Conversão alimentar } \\
\text { Feed:gain ratio }\end{array}$} \\
\hline & $\begin{array}{l}\mathrm{SES}^{2} \\
E S U^{2}\end{array}$ & $\begin{array}{r}\text { SEN } \\
E S S\end{array}$ & $\begin{array}{c}\text { SESP } \\
E S O\end{array}$ & $\begin{array}{l}\text { Média } \\
\text { Mean }\end{array}$ & $\begin{array}{l}\mathrm{SES}^{2} \\
E S U^{2}\end{array}$ & $\begin{array}{l}\text { SEN } \\
E S S\end{array}$ & $\begin{array}{l}\text { SESP } \\
E S O\end{array}$ & $\begin{array}{l}\text { Média } \\
\text { Mean }\end{array}$ & $\begin{array}{l}\mathrm{SES}^{2} \\
E S U^{2}\end{array}$ & $\begin{array}{l}\text { SEN } \\
E S S\end{array}$ & $\begin{array}{l}\text { SESP } \\
E S O\end{array}$ & $\begin{array}{c}\text { Média } \\
\text { Mean }\end{array}$ \\
\hline $\begin{array}{l}\mathrm{CM}(-)^{1} \\
M C(-)^{I}\end{array}$ & 457,93 & 636,49 & 468,75 & $526,31^{\mathrm{b}}$ & 821,53 & 896,56 & 833,63 & $852,92^{\mathrm{a}}$ & 1,80 & 1,41 & 1,78 & $1,65^{\mathrm{a}}$ \\
\hline $\begin{array}{l}\mathrm{CM}(+) \\
M C(+)\end{array}$ & 479,18 & 663,33 & 480,53 & $546,57^{a}$ & 821,94 & 890,56 & 830,56 & $848,87^{\mathrm{a}}$ & 1,71 & 1,34 & 1,73 & $1,58^{b}$ \\
\hline $\begin{array}{l}\text { Média } \\
\text { Mean }\end{array}$ & $468,56^{\mathrm{B}}$ & $649,90^{\mathrm{A}}$ & $474,90^{\mathrm{B}}$ & & $820,73^{\mathrm{B}}$ & $893,74^{\mathrm{A}}$ & $832,09^{\mathrm{B}}$ & & $1,74^{\mathrm{B}}$ & $1,38^{\mathrm{A}}$ & $1,75^{\mathrm{B}}$ & \\
\hline Anova & & & & $\begin{array}{r}\text { Proba } \\
\operatorname{Pr} \\
\end{array}$ & $\begin{array}{l}\text { oilidade do } \\
\text { bability } F\end{array}$ & $\begin{array}{l}\text { teste } \mathrm{F} \\
\text { st }\end{array}$ & & & & & & \\
\hline $\begin{array}{l}\text { Soja } \\
\text { Soybean }\end{array}$ & 0,001 & & & & 0,001 & & & & 0,001 & & & \\
\hline $\begin{array}{l}\text { Enzima } \\
\text { Enzyme }\end{array}$ & 0,020 & & & & 0,790 & & & & 0,010 & & & \\
\hline $\begin{array}{l}\text { Soja*Enzima } \\
\text { Soybeans *Enzyme }\end{array}$ & 0,770 & & & & 0,990 & & & & 0,850 & & & \\
\hline CV (\%) & & 5,35 & & & & 6,12 & & & & 5,73 & & \\
\hline
\end{tabular}

$A, B$ Médias seguidas de letras distintas na mesma linha são diferentes $(P<0,05)$ pelo teste SNK.

$A, B$ Means followed by the different letteres within a row differ $(P<0.05)$ by SNK test.

a,b Médias seguidas de letras distintas na mesma coluna são diferentes $(P<.05)$ pelo teste SNK.

$a, b$ Means followed by the different letteres within a column differ $(P<0.05)$ by SNK test.

${ }^{1}$ Complexo multienzimático: sem (-) e com (+).

1 Multienzymatic complex: without (-) with (+).

2 SES = soja extrusada subprocessada, SEN = soja extrusada com processamento normal, SESP = soja extrusada superprocessada.

2 ESU = extruded full fat soybean under processed, ESS = extruded full fat soybean stander processed, ESO = extruded full fat soybean over processed.

ação de enzimas digestivas, enquanto o superprocessamento diminui o valor nutricional, pela formação da reação de Maillard.

Nas aves alimentadas com dietas formuladas à base de SES, SEN e SESP, registraram-se pesos relativos de pâncreas de 0,699; 0,392; e 0,603 g/100 g de PV, respectivamente, indicando que as dietas formuladas com SES e SESP proporcionaram os maiores pesos de pâncreas $(\mathrm{P}<0,05)$. Essa hipertrofia pancreática pode ser atribuída à compensação das perdas provocadas pelos fatores antinutricionais (lectinas, inibidores de tripsina e saponinas) ou pelas perdas de qualidade provocadas pelo superaquecimento, observadas em sojas sem adequado processamento.

Zhang \& Parson (1993) também observaram que frangos de corte dos 7 aos 21 dias de idade alimentados com soja extrusada com 2,20 de atividade ureática apresentaram peso de pâncreas de $0,694 \mathrm{~g}$ (\%PV) e ganho de peso de $233 \mathrm{~g}$, enquanto aqueles alimentados com dieta à base de soja extrusada com 0,10 de atividade ureática apresentaram peso do pâncreas de $0,350 \mathrm{~g}$ (\%PV) e ganho de peso de $268 \mathrm{~g}$.

Diferenças no desempenho de aves alimentadas com soja extrusada em diferentes níveis de processamento também foram relatadas por Sakomura \& Silva (1998a), que notaram que o desempenho de aves alimentadas com dietas formuladas com soja integral extrusada foi superior ao daquelas que consumiram dieta à base de farelo de soja, o que pode ter sido conseqüência do maior teor de óleo na soja integral e na atividade antitripsínica (UTI/mg PB), que foi maior no farelo de soja.

Entre as dietas contendo complexo multienzimático (CM), independentemente do processamento da soja, houve aumento médio $(\mathrm{P}<0,05)$ de $3,85 \%$ no ganho de peso e melhoria de $4,44 \%$ na conversão alimentar das aves alimentadas com dietas à base de soja extrusada.

Apesar de não existir interação significativa entre a adição do $\mathrm{CM}$ e o tipo de processamento da soja, a presença das enzimas aumentou $(\mathrm{P}<0,05)$ o ganho de peso em 4,64; 4,22; e 2,51\% e a conversão alimentar em 5,0; 4,96; e $2,81 \%$ nas aves que receberam as dietas à base de SES, SEN e SESP, respectivamente.

As aves alimentadas com dietas à base de soja extrusada subprocessada e suplementadas com o CM apresentaram, numericamente, os melhores valores de ganho de peso e conversão alimentar. Este efeito de maior ação das enzimas sob a soja extrusada subprocessada foi também observado por Brito et al. (2005), que notaram maior aumento nos coeficientes de digestibilidade da matéria seca, proteína bruta e energia bruta em dietas formuladas com SES com a adição de enzimas. 
Figueiredo et al. (1998) constataram, em frangos de corte de 1 a 41 dias de idade, aumentos $(\mathrm{P}<0,05)$ de $1,9 \%$ para ganho de peso e de 1,6\% para conversão alimentar quando adicionaram um complexo de enzimas composto de protease, amilase e xilanase em dietas formuladas à base de milho e de farelo de soja, de milho e de soja extrusada ou de milho e de soja tostada.

Melhor desempenho de frangos de corte com a suplementação de enzimas à dieta foi observado também por Schang et al. (1997), Cousins (1999) e Zanella et al. (1999b), que relacionaram essa melhoria à maior digestibilidade de proteína bruta, energia bruta e fibra, à redução dos fatores antinutricionais e à melhor utilização da energia, como observado por Charlton (1996), Hew et al. (1998), Danicke et al. (2000), Choct (2002) e Brito et al. (2005)

Segundo Zanella et al. (1999), a inclusão de enzimas exógenas reduz a produção endógena de amilase em $23,4 \%$ e a de tripsina pancreática em $35,8 \%$, o que poderia favorecer a síntese protéica no tecido muscular, pela maior disponibilização dos aminoácidos.

\section{Conclusões}

A adição do complexo multienzimático composto de protease, amilase e celulase em dietas à base de soja extrusada melhorou o ganho de peso $(3,8 \%)$ e a conversão alimentar $(4,24 \%)$ de pintos de corte de 1 a 21 dias de idade.

As aves alimentadas com dietas contendo soja extrusada normal apresentaram melhor desempenho em relação às alimentadas com as sojas extrusada sub e superprocessada.

\section{Agradecimento}

À Alltech Agroindústria do Brasil Ltda, pelo fornecimento do complexo multienzimático Allzyme Vegpro ${ }^{\circledR}$, e à Fundação de Coordenação de aperfeiçoamento de Pessoal de Nível Superior (CAPES), pela concessão da bolsa de estudo.

\section{Literatura Citada}

ASSOCIAÇÃO NACIONAL DOS FABRICANTES DE RAÇÕES - ANFAR. Matérias-primas para a alimentação animal. São Paulo: 1985. BRITO, C.O.; ALBINO, L.T.F.; ROSTAGNO, H.S. et al. Adição de complexo multienzimático em dietas à base de diferentes sojas extrusadas sobre a digestibilidade de nutrientes e valores energéticos em pintos de corte. Revista Brasileira de Zootecnia, (em andamento), 2005.

CHARLTON, P. Expanding enzyme applications: higher amino acid and energy values for vegetable proteins. In: ALLTECH'S ANNUAL SYMPOSIUM, 12., 1996, Loughborough. Proceedings... Loughborough: Nottingham University Press, 1996. p.317.

CHOCT, M. Non-starch polysaccharides: effect on nutritive value In: Poultry feedstuffs: supply, composition and nutritive value In: MACNAB, J.M.; BOORMAN, K.N. (Eds.) Factors influencing nutritive value. Edinburgh: $\mathrm{CAB}$ Internacional.
2002. p.221-235

COUSINS, B. Enzimas na nutrição de aves. In: I SIMPÓSIO INTERNACIONAL ACAV-EMBRAPA SOBRE NUTRIÇÃO DE AVES, 1999, Concórdia. Anais... Concórdia: Centro Ncional de Pesquisa de Suínos e Aves, 1999. p.118-132.

DANICKE, S.; JEROCH.; H.; BOTTCHER, W. et al. Interactions between dietary fat type and enzyme supplementation in broiler diets with high pentosan contents: effects on precaecal and total tract digestibility of fatty acids, metabolizability of gross energy, digesta viscosity and weights of small intestine. Animal Feed Science and Technology, v.84, p.79-294, 2000.

FARAG, M.D.E. The nutritive value for chicks of full-fat soybeans irradiated at up to $60 \mathrm{kGy}$. Animal Feed Science and Technology, v.73, p.319-328, 1998.

FIGUEIREDO, A.N.; ZANELLA, I.; SAKOMURA, N.K.L. et al. Efeito da adição de enzimas em dietas à base de milho e tipos de soja sobre o desempenho de frangos de corte. In: CONFERÊNCIA APINCO DE CIÊNCIA E TECNOLOGIAS AVÍCOLAS, 1998, Campinas. Anais... Campinas: 1998. p.36.

GARCIA, E.R.D.M.; MUKARANI, A.E.; BRANCO, A.F. Efeito da suplementação enzimática em rações com farelo de soja e soja integral extrusada sobre a digestibilidade de nutrientes, o fluxo de nutrientes na digesta ileal e desempenho de frangos. Revista Brasileira de Zootecnia, v.29, p.1414-1426, 2000.

HEW, L.I.; RAVINDRAN, V.; MOLLAH, Y. et al. Influence of exogenous xylanase supplementation on apparent metabolisable energy and amino acid digestibility in wheat for broiler chickens. Animal Feed Science and Technology, v.75, n.2, p.83-92, 1998.

JARORI, D.; SCHEIDELER, S.E. et al. The effect of dietary wheat middling and enzyme supplementation. 1. late egg production efficiency, egg yields, and egg composition in two strains of leghorn hens. Poultry Science, v.78, p.841- 847, 1999.

JORGE NETO, G. Soja integral na alimentação de aves e suínos. Avicultura Industrial, n.998, p.4-15, 1992.

ITCHEN, D.I. Enzyme applications in corn/soya diets fed pigs. In: BIOTECHNOLOGY IN THE FEED INDUSTRY PROCEEDINGS OF ALLTECH'S 13Th ANNUAL SYMPOSIUM, 1997, Loughborough, Leics. Anais... Loughborough: Nottingham University Press, 1997. p.01-114.

MARSMAN, G.J.P.; GRUPPEN, H.; Van der POEL, A.F.B. et al. The effect of shear forces and addition of a mixture of a protease and a hemicellulase on chemical, physical and physiological parameters during extrusion of soybean meal. Animal Feed Science and Technology, v.56, n.1-2, p.21-35, 1995.

ROSTAGNO, H.S.; ALBINO, L.F.T; DONZELE, J.L. et al. Tabelas brasileiras para aves e suínos: composição de alimentos e exigências nutricionais. Viçosa, MG: Universidade Federal de Viçosa, 2000. 141p.

SAKOMURA, N.K.; SILVA, R.D. Avaliação da soja integral tostada ou extrusada sobre o desempenho de frangos de corte. Revista Brasileira de Zootecnia, v.27, p.584-594, 1998a.

SCHANG, M.J.; AZCONA, J.O.; ARIAS, J.E. The performance of broilers fed with diets containg allzyme vegpro. In: BIOTECHNOLOGY IN FEED INDUSTRY ALLTECH'S ANNUAL SYMPOSIUM, 13., 1997, Nicholasville. Anais... Nicholasville: 1997. p.95-100.

SMITH, O.B. Why extrusion looking? Cereal Food World, v.21, p.4-8, 1976

UNIVERSIDADE FEDERAL DE VIÇOSA - UFV. SAEG - Sistema de análises estatísticas e genéticas. Viçosa, MG, 2000.

ZANELLA, I.; SAKOMURA, N.K.; SILVERSIDES, F.G. et al. Effect of supplementation of broiler diets based on corn and soybeans. Poultry Science, v.78, p.561-568, 1999b.

ZHANG, Y.E.; PARSONS, C.M. Effect of extrusion and expelling on the nutritional quality of conventional and kunitz trypsin inhibitor-free soybeans. Poultry Science, v.72, p.2299-2308, 1993.

Recebido: 05/08/04 Aprovado:22/09/05 